\title{
DYNAMICS OF AN INVINCIBLE TROOP FORMATION IN ANCIENT OPEN BATTLEFIELDS
}

\author{
Kishore Dutta*
}

\author{
Department of Physics, Handique Girls' College \\ Guwahati, India
}

DOI: 10.7906/indecs.19.1.12

Regular article

\begin{abstract}
One of the most enthralling ancient magical battle formation tactics is the Chakravyuh -- a multilayer dynamic defensive structure, which was used in the 18-days long Kurukshetra war as described in the great Indian epic Mahabharata and in many subsequent scriptures. Unfortunately, none of the existing literature address its inner details or the skills involved and, as such, its working still shrouds in mystery. What makes it nearly invincible even for an exceptionally skilled warrior? How a huge troop was controlled, organized, and restructured from the core of the Chakra? What are the governing rules for maintaining the structure even in the time of extreme hardship in the battlefield? In quest of the answers to such technical questions, while we made attempts to explore and decipher the inner details of Chakravyuh, we find some descriptions that differ geometrically from each other. Despite such variants of the structure, here we would like to bring into focus the common inner mechanism of such a multilayer organizational strategy that, in turn, confirms its inherent geometry. It reveals how, because of synchronize maneuvers, the direction of rotation of the Chakra about its axis is closely interwoven with the direction of movement of the infantrymen. The fact that relative spinning motion has adverse psychological impact in diminishing mental power, seems to be the foremost principle behind the design of its dynamics that slowly push on an invading warrior towards one of the dead-ends that are created by restructuring the Chakra out of nearly infinite possible ways.
\end{abstract}

\section{KEY WORDS}

Chakravyuh, relative spinning motion, logarithmic spiral, equilateral triangle

\section{CLASSIFICATION}

JEL: $\quad$ H79

Pacs: $\quad$ 02.40.Pc, 87.23.Kg, 89.90.+n, 89.20.Dd 


\section{INTRODUCTION}

Myths, histories, and mysteries of the ancient great wars, on the one hand, mesmerize the human mind in discriminating good and evil, justice and injustice, ethics and immorality, power and incapability, loyalty and treachery and, on the other hand, ignite a passion for understanding the ancient tactics and strategies of warfare that bear witness to a towering vision of transcendence. Whatever the cause for the outbreak of an open battle, it is the tactics and strategies of warfare that finally determine the victory and defeat. Different styles of warfare in ancient India are described in the Vedic literature (1500-1000 BCE), the two Sanskrit epics Ramayana and Mahabharata (1000-600 BCE), Kautilya's Arthashastra (c. $4^{\text {th }}$ century BCE), Banabhatta's Harshacharita (c. $7^{\text {th }}$ century BCE) and in many other scriptures [1-4]. One of the ancient great battles, described in the epic Mahabharata and in many subsequent scriptures, is the war of Kurukshetra that lasted 18-days long [5]. Among the various tactical battle arrays that were used by the warriors in the Kurukshetra war as a defensive as well as an offensive tool, one of the deadliest troop formation tactics was the Chakravyuh - a system of magical defense, the working method of which shrouded in mystery. Dronacharyya - the renegade Brahman, the master of martial arts and the commanderin-chief of the Kaurava army, formed the Chakravyuh on the $13^{\text {th }}$ day of the war to trap and kill Abhimanyu - the son of Arjuna and an invincible legendary youngest warrior of that time. Being one of the deadliest war strategies, the structure and its formation mystified humans from ancient times. How ingeniously it was designed and what is the level of complexity of such a structure? Why does it remain invincible even for a highly skilled warrior and what geometry is involved in its construction? Vedic literature and the Sanskrit epics Ramayana and Mahabharata composed in ancient India refer to battle formations as diverse as Chakravyuh (wheel formation), Krauncha vyuh (heron formation), Mandal vyuh (galaxy formation), Suchivyuh (needle formation), Chandrakalavyuh (Crescent moon formation), Makaravyuh (scorpion formation), and many others. The Yuddhakanda of the Mahabharata (composed around $400 \mathrm{BCE}$ ) refers to these tactical configurations as the characteristic Indian way of war fighting with few abstract details. Other subsequent scriptures such as Kautilya Arthashastra, Manusamhita, Kamandaka Nitisara, described the strategies and tactics of such ancient Indian warfares without offering inner details. According to these scriptures, the formation of Chakravyuh resembles with that of a hurricane or a tornado. It sucks in and eats up everything on its path and before the enemy realises it's effects, the human vortex shifts in opposite directions and brings in a newer battling force, thereby tiring the opponent to an utter psychological, physical and resourceless defeat.

Since none of the existing ancient scriptures addressed the inner details or the skills involved $[6,7]$, the subsequent attempts in understanding the working principle of Chakravyuh differ significantly, both structurally and functionally. Although several recent works on ancient India's military history have come up [8-12], there has been hardly any attempts in revealing the underlying strategies of such an ancient marvel. The carvings on the Halebidu temple of Mysore that was supposed to have constructed during the $12^{\text {th }}$ and $13^{\text {th }}$ centuries A.D. contain a structure of Chakravyuh which can be sketched as shown in Fig. 1. Although this structure has long been treated as a template in describing Chakravyuh, there are some other descriptions where entirely different labyrinth structures are used. Here we would like to bring into focus all such possible structures and their geometry. We shall emphasize the structure engraved in the Halebidu temple which is, from a geometrical point of view, a relatively simple seven-layered structure. It reveals that the direction of rotation of the Chakra about its axis is closely interwoven with the direction of movement of the infantrymen. We shall also discuss some other structures and show how all such geometry leads to nearly infinite possible ways of restructuring the Chakra to create final dead-ends. 
The fact that relative spinning motion has an adverse psychological impact in diminishing mental power seems to be the foremost principle behind the design of its dynamics that finally push on an invader towards a victim of indiscriminate slaughter due to continuous multi-directional attack of strategically distributed strength of soldiers in the layers of the Chakravyuh. We also show the underlying tricks of its construction using some elementary geometry, with a hope that it may help unravel the magic, stimulate ideas, and spark curiosity among the readers.

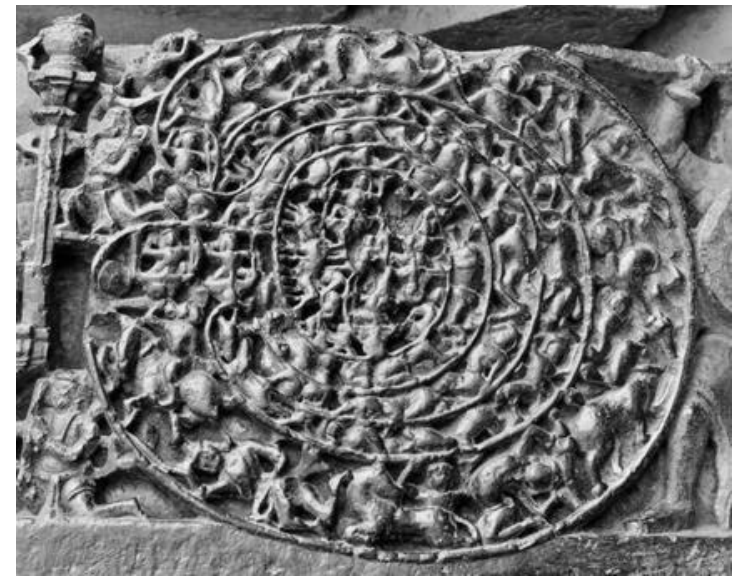

(a)

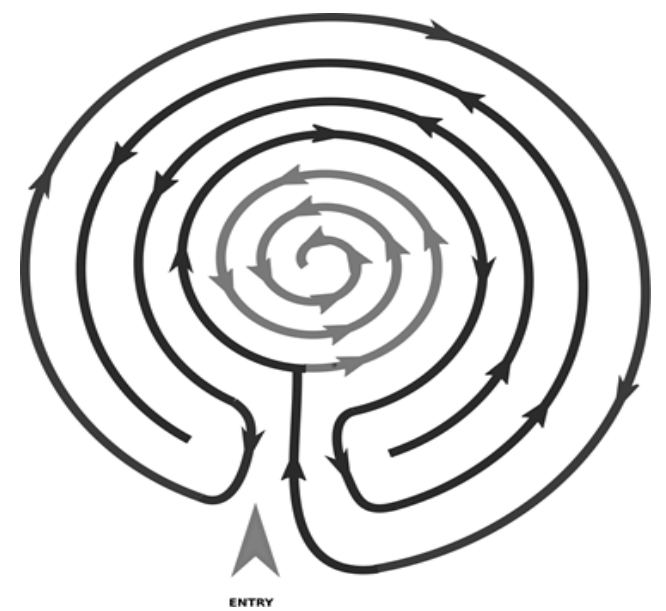

(b)

Figure 1. (a) The carving of Chakravyuh in the temple of Halebidu, Mysore (India) [13] (b) A sketch showing the top view of the trajectories of a Chakravyuh that form its multilayer structure. In this structure, there are seven layers and arrows indicate the direction of the soldier's movement in each layer.

\section{ORGANIZATION OF THE ARRAY}

Most of our description here is based on the structure engraved in the temple of Halebidu. Moreover, we shall also briefly describe some other possible seven-layered structures where the same principle as describes here is applicable regarding the organization of the troop.

\section{DEFENSIVE MANOUVRE}

Being a multilayer defensive structure, Chakravyuh remains one of the deadliest formations ever known [14]. As schematically depicted in Figure 1, a Chakravyuh comprises of seven layers of soldiers where weak and strong warriors are strategically placed in each of the layers, either to impose maximum damage on the opposing warriors or to defend the attacks from highly skilled enemy warriors. Soldiers of the inner level are technically and physically stronger than the soldiers on the outer level. The Infantry form the outer layers while the inner layers are formed by armored chariots and elephant cavalry (fought on the back of elephant). The innermost level consists of the strongest soldiers with a relatively higher density than that of the outer layers. The highly skilled warriors including the commander himself take positions near the core of the Chakra so that any devastating projectile attack on the vyuh can be easily neutralized. Each layer has a concealed entrance that is closely protected by one of the highly skilled warriors and his personal troops. The role of soldiers in the outer layers is to only conceal the entry of enemy warrior into the layer. If a layer breaks down, the outer layer soldiers conceal further entries and not attack the warriors who already breached the layer. The whole arrangement that looks like a disc when viewed from above, has a mechanism of synchronous rotation about its axis. As we describe below, the rotation of the Chakra and the oppositely directing movements of the soldiers in two successive layers 
are closely interwoven, making it a puzzled arrangement of soldiers who keep moving in a spinning wheel. In addition to rotation about the axis, the Chakravyuh also revolves in its orbit and, on such rotating and revolving tracks, the whole arrangement of soldiers moves continuously across the battlefield like a typhoon and destroys everything whoever comes in its path. The entrance acts like a mouth that slowly and steadily engulfs an enemy warrior, an enemy troop, and the entire enemy army. However, the Chakravyuh does not move around the battlefield for the sake of destruction. Being a dedicated mission of making captive and bringing the target into custody, it only focuses on and dedicates to accomplishing goals, no matter whatever barrier comes in its way.

\section{TRIGGERING SYNCHRONIZE MOVEMENTS}

The very essence of any defensive maneuver is the synchronized movement. In order to visualize how the soldiers synchronize their movement on the layers, let us begin with the nascent formation (Fig. 1) with neither any roadblocks nor any dead ends. Such roadblocks and dead ends that are created according to the commander's order only after the enemy is trapped in the maze, are the results of some rearrangement on this bare structure. In order to capture the targeted warrior, the bare formation moves across the battlefield. The outer levels, shown black in Fig. 1, are formed by tightly packed infantry equipped with close combat weapons such as spear, sword, and shield so as not to allow the incoming chariot to breach the layer easily. The direction of the soldier's movement in these outer layers (black spirals) is triggered by the position of the black dot shown in Fig. 2(a). The soldier who takes this position is responsible to initiate anticlockwise motion by taking a step forward. This triggers a chain reaction as each soldier in the same ring needs to move a step forward to take up the empty position, as shown in Fig. 2(b). This sliding motion propagates throughout the entire black rings, resulting in both clockwise and anticlockwise motion.

In the inner rings shown in red, the direction of movement is initiated concurrently from the position of the red dot. The soldier who takes this position makes a forward step and triggers the chain reaction following which every soldier on the same (red) ring makes a sliding motion to fill up the empty space. In this way, soldiers maintain their movement in all the seven circular trajectories in an alternate clockwise and anticlockwise rotation, and, as a result, the whole Chakra spins in an anticlockwise direction about its axis, as shown in Fig. 2. This direction would be easily reversed (clockwise) if the soldiers start moving in a direction opposite to that of Fig. 2.

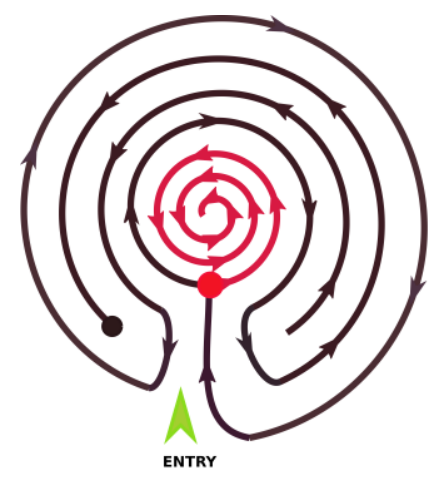

(a)

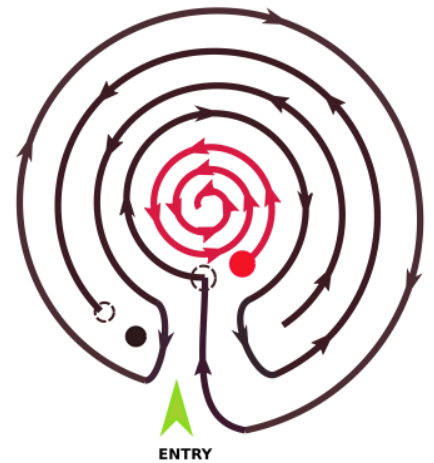

(b)

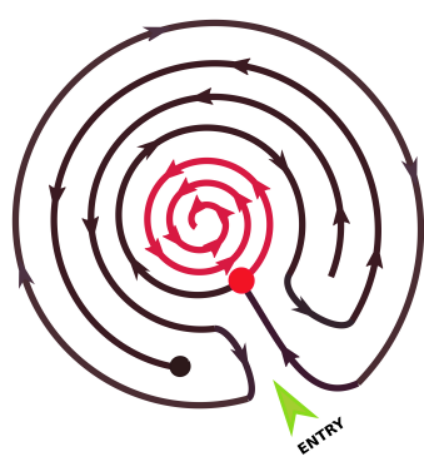

(c)

Figure 2. Synchronize movements of infantrymen and the resulting spinning motion of the Chakra. (a) The directions of movement are triggered by the positions of the black and red dots in black and red rings, respectively. (b) Soldier's forward sliding motion create gaps at the position of red and black dots (c) In order to fill up the gaps, the soldiers move continuously on the tracks that initiate rotation of the whole arrangement about its axis. 
In order to make a Chakravyuh nearly invincible, maintaining a perfect synchronized movement among the entire array is very much necessary. As we have seen, it is this synchronized motion that makes the entire wheel spin on its axis. That the rotation of the Chakra is closely interwoven with the direction of movement of the soldiers is the key to the perplexing puzzle. Being a massive structure, the fast movement of soldiers in the outer layers creates a web of deceit looking at which the enemy would be completely lost into thinking that the formation is in few numbers as the insurmountable strength of the inner rings cannot be estimated from outside the formation.

The synchronized motion of the soldiers on the layers holds a vital clue that may help in deciphering the potentially viable structures of a Chakravyuh. The structure that we have shown above (Figs. 1 and 2) can be constructed from a spiral, a step-by-step procedure of which is described in Section 5. One can think of its construction from concentric circles but in that case, synchronization would not be possible on the resulting structure. Some existing literature mentioned another seven-layered structure as a Chakravyuh which is made of concentric circles, as shown in Fig. 3(a). However, one can easily figure out that the above mentioned perfect synchronized motion would be impossible here and, as such, it is just a labyrinth structure and not a Chakravyuh unless we make it from spirals, as shown in Fig. 3(b). Although the structure shown in Fig. 3(b) differs from that of Fig. 1, it would perform the same type of spinning motion as described in Fig. 2.

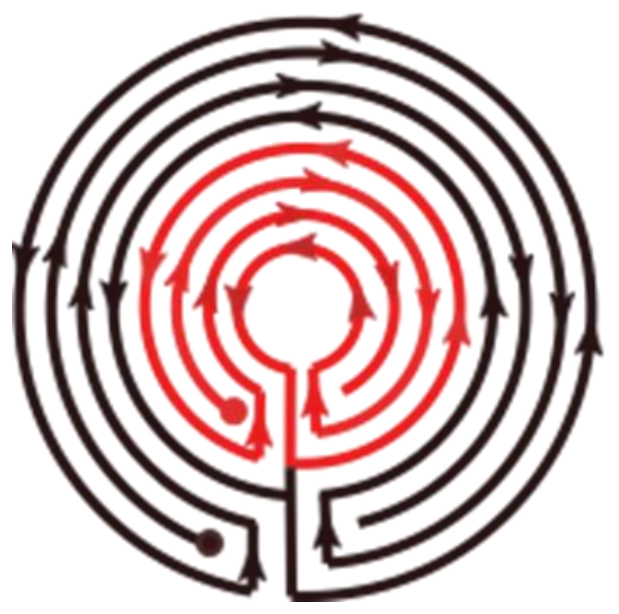

(a)

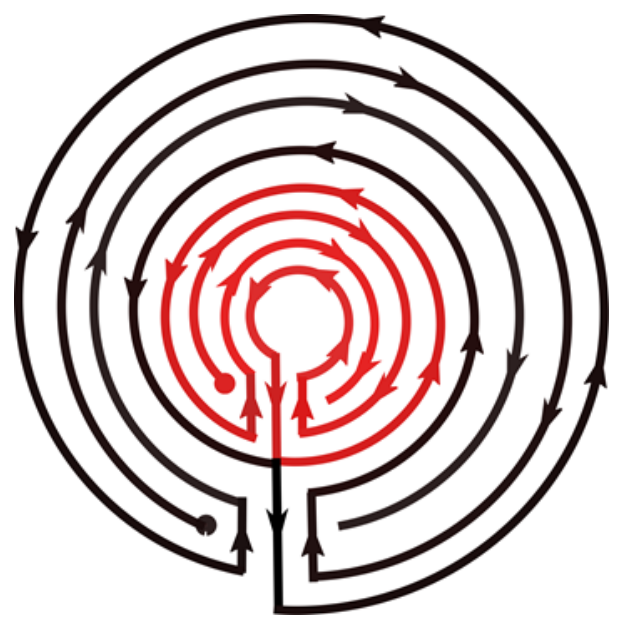

(b)

Figure 3. Another two seven-layered structures which are constructed from (a) concentric circles and (b) a spiral. The synchronized motion is possible only on the structure shown in (b).

\section{ENSURING A TIGHT COORDINATION AMONG THE TROOP}

On the battlefield, war drums, conch shells, and other musical instruments are effectively used in order to maintain perfect harmony in the movement of infantrymen. Depending on the needs, the commander controls the direction as well as the speed of movement with the help of some special drumbeats or blowing a conch in a particular note. Maintaining order during the movement is very much necessary as any gap in the chain of infantryman could be fatal, if exploited. If any soldier in the formation gets killed, his position is immediately covered up by the sliding motion of the soldiers following him, thereby ensuring the existence of the whole maze even in the time of extreme hardship. Skilled archers in armored chariots, cavalry, and elephants on the inner level can easily fire arrows on the heads of infantrymen on the outer layer to kill the infantrymen of enemy warriors. This formation ensures the safety of the infantry from enemy warriors who are trying to breach the Chakravyuh. 
The spinning motion of the entire Chakra is also highly advantageous. As soon as the targeted warrior gets trapped inside, a big troop of enemy warriors from outside might repeatedly try to breach the layers. By shifting the entrance to other places, the commander creates illusions among such follower enemy troops. Due to the rotation of the Chakra, the enemy troop must face the attacks of fresh warriors from inside, thereby quick destruction of the entire enemy force is possible. By the time, if some follower makes his way to follow the already trapped warrior, he will have completely lost track of the direction he managed to enter into the enemy rank.

\section{TRICKS OF THE TRADE}

Being such tight coordination among the troop, it is exceedingly difficult to breach the layers even for a skillful warrior as any attack by invading warriors in the outer layer draws concentrated attention and multidirectional attack of all centered archers. It is this strategic organization of soldiers in layers that makes a Chakravyuh a great defensive formation. Fighting inside such a ruthless spinning death machine has an adverse psychological impact that severely damages the mental power of the enemy warrior. Here we shall see how such a well-planned design can be deployed either as an offensive or as a defensive tool.

\section{AS AN OFFENSIVE SYSTEM}

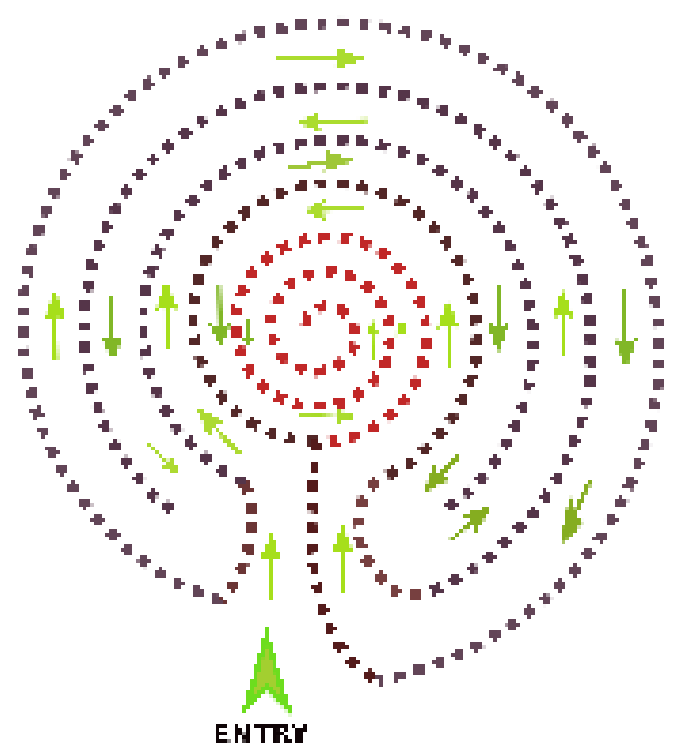

Figure 4. The direction of movement of an enemy warrior while entering through the entrance of a steady non-rotating Chakravyuh.

The Chakravyuh was ingeniously designed to trap and kill those fierce warriors who appeared to be disastrous on the battlefield and whose presence created terrible fear of attack among the opponents. The well-planned strategy to attack such a warrior in a coordinated manner is to trap him in a Chakravyuh. The moment the targeted warrior enters through the entrance of the maze, the entrance gets sealed and the warrior gets trapped by the soldiers of the fourth layer. Most often, this happens unknowingly because while a warrior is in the thick of battle, it is difficult for him to get a sense of what is happening across the field; there would be just the warrior and the next person to kill or to be killed by. Although the targeted warrior gets the feeling that something had happened to change the dynamic as there would be no sign of main opponent warriors in his immediate vicinity, he wonders as if the opponents are facing their own problems elsewhere on the field. He would be unable to realize the narrow path as the entrance of some well-planned formation simply because of the 
sheer size of the entire formation. For him, it appears as a traditional battle where a wave of soldiers is coming and another wave of soldiers are going way and, amidst all such upheaval, he would find a free lane and enters the right way, thereby being trapped.

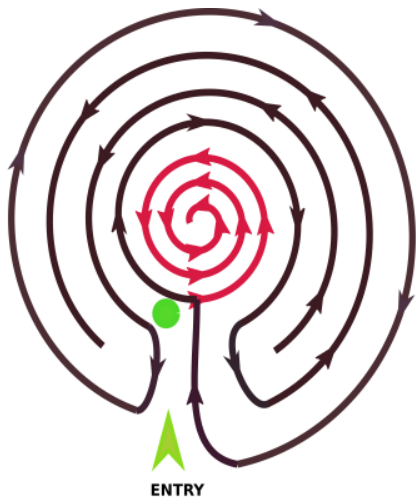

(a)

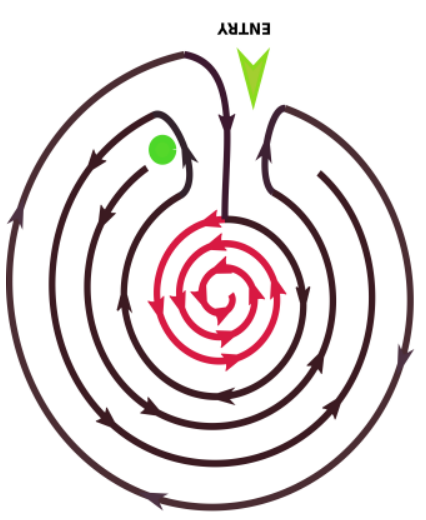

(d)

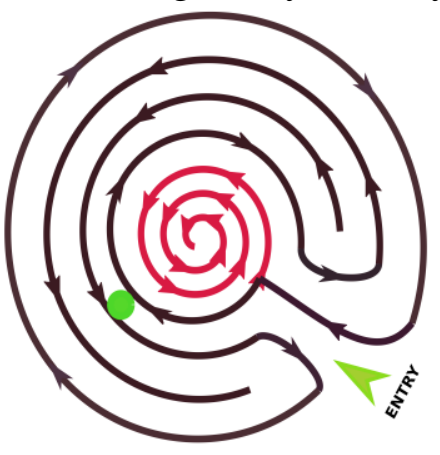

(b)

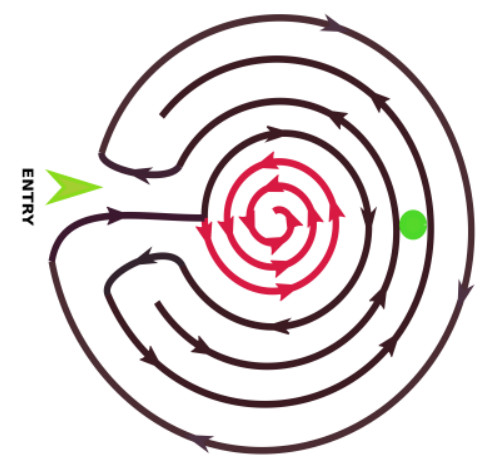

(e)

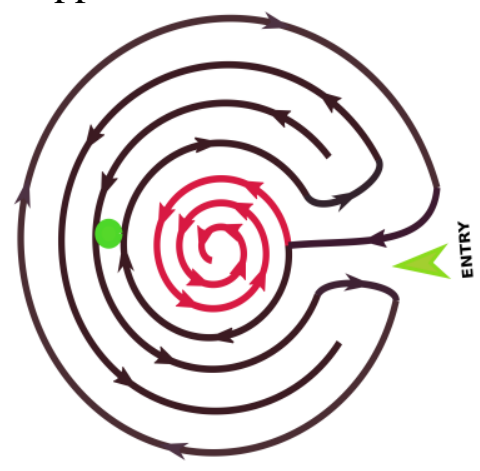

(c)

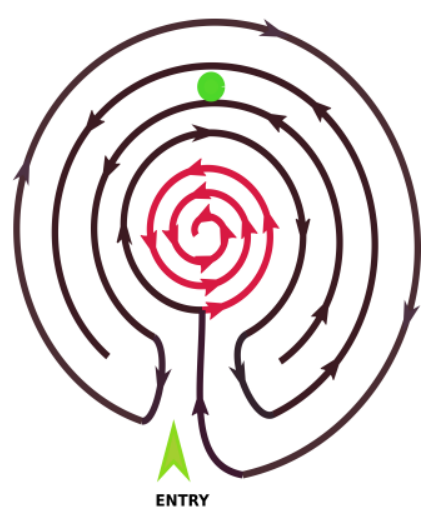

(f)

Figure 5. Anticlockwise rotation of the Chakra. The green dots represent the successive positions of an incoming enemy warrior. The relative speed of the warrior depends on the speed of rotation of the Chakra and the speed of the warrior.

The entrance is heavily fortified by a strong and skilled warrior and his troop to ensure that no other enemy warriors can enter the maze to help the already trapped warrior. Being trapped in the maze, the targeted warrior may remain standstill or keeps running in a circular motion along the allowed path as depicted in Fig. 4. In either case, he must face the attack of new and fresh soldiers. This is because, although he decides to stand still, the whole formation can be kept rotating continuously about its center. Thus, there appears a relative motion between the incoming warrior and the whole mess, as depicted in Fig. 5. While the incoming warrior is in stand still position, the chakra is revolving continuously in anticlockwise direction about its centre. As a result, the position of the warrior keeps changing with the rotation of the chakra. By observing his movement, the commander of the troop passes the signal to his soldiers on how to change their movement and speed. Depending upon the strategy of attack on the targeted warrior, the commander can either speed up or stop the rotation of the Chakra. In any case, the targeted warrior must move across the perimeter of each layer. If somehow he is successful in traversing one layer, he would end up fighting the stronger soldiers in the innermost layer. If the warrior is successful in killing many soldiers of a particular layer, then he is forced to go inside another layer to get attacked by more ferocious and seasoned warriors. As a result, as he enters deep and deep 
inside the Chakra, he keeps getting tired both physically and mentally and eventually, becomes the victim of indiscriminate slaughter.
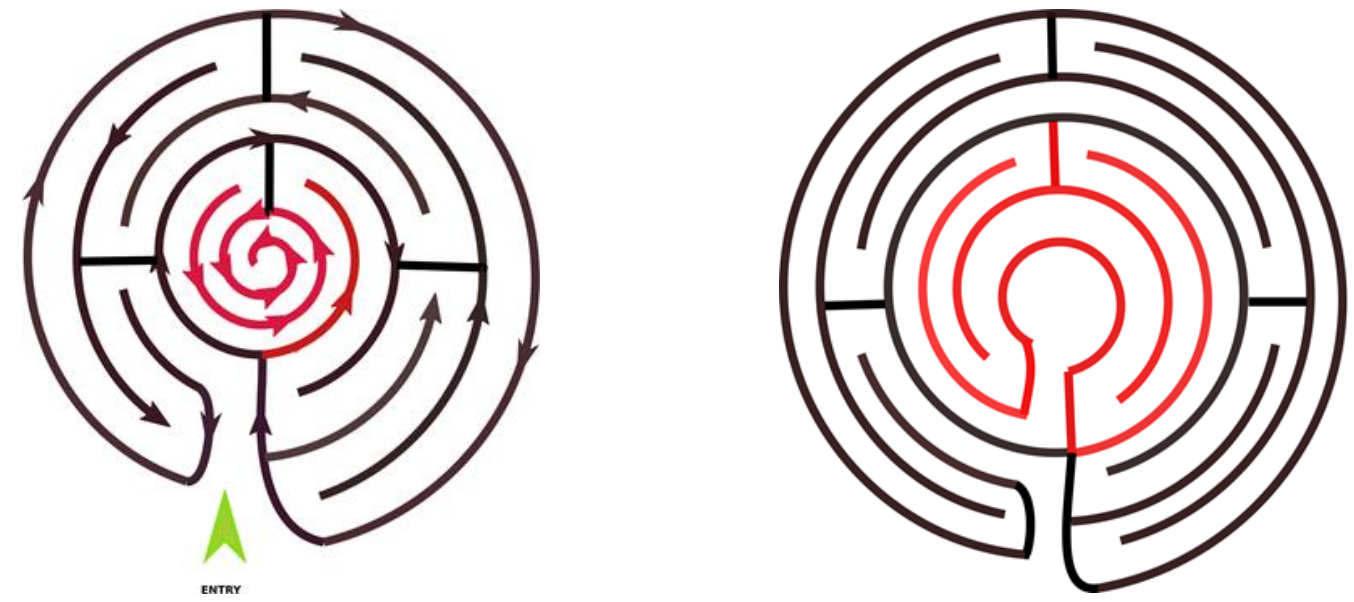

Figure 6. Rearrangement of the Chakra by creating more roadblocks. The two different configurations correspond to two different nascent structures.

But that is not the whole scenario. At any moment, by assessing the strength of invasion, the commander can change the design of the formation to a necessary extent. Being a dynamic multilayer structure, the Chakra can be rearranged meticulously in several ways. The commander can restructure the entire maze by creating roadblocks as many as he can manipulate out of nearly infinite possible ways; one such configuration is shown in Fig. 6. By creating more roadblocks, the enemy can be pushed to a more restricted area and finally towards the dead-end. The dead-ends are the outcome of creating more and more roadblocks and turnings on the nascent structure, turning back from which is nearly impossible even for a seasoned warrior unless he destroys the formation. However, as the maze gets more and more complicated, creating chaos within the maze would not be difficult for a well-trained warrior. To destroy such a ferocious warrior with minimum effort and least damage from own side, the exact creation of such roadblocks and final dead-ends requires a high level of computation. This might be the reason as to why only a very few exceptional warriors during the time of Mahabharata possessed the knowledge of the execution of Chakravyuh.

\section{AS A DEFENSIVE SYSTEM}

It is interesting to see how a Chakravyuh remains as an almost impenetrable defensive system. In order to defend someone in an open battle or if the chief target of the enemy is known beforehand, Chakravyuh is the ultimate solution where the enemy's target can be well-protected by keeping him at the core of the Chakra. As already described above, the soldiers near the entrance are always stronger and more skilled compared to the remaining regions. As such, the enemy warriors are most likely to get killed if enter through the opening. If the enemy forces somehow manage to enter through the entrance, they cannot directly rush to the heart of the formation without breaching the layers. If the enemy forces want to reach the center without applying any thrust to break the layers, they need to move across the perimeters of each layer. Due to the massive size of the Chakravyuh, such a long journey alone would be enough for the enemy to catch their breath.

An alternative but a preferable tactic to reach the target is to enter straight towards the center by killing as many soldiers as possible so as to increase the gap between them which later can be easily breached by the warriors following him. This is possible only for seasoned warriors; ordinary warriors will no longer be successful in breaching the layer by killing soldiers in front of them, as the gap will be instantly covered by the sliding soldiers. Being a self-healing 
machine, the Chakravyuh takes the lives of inexperienced warriors who challenge and attempt to breach the layers. As soon as the enemy troop starts breaching layers, the commander manipulates the structure and creates roadblocks out of varieties of permutations and combinations to surround and then to crush the enemy. Only a highly skilled warrior with piercing intelligence can breach all the seven layers and able to approach the target.

\section{THE ROUTE TO ENTER AND ESCAPE}

Entering and exiting from such a well-planned defensive fortification is an almost impossible task unless a warrior possesses the highest degree of training, extremely fast analytical power, and mental strength. This is because, in both the offensive and defensive maneuvers, the Chakravyuh can simultaneously impose a three-fold attack --- physical, psychological, and strategic. The warrior must come up from the illusions of relative spinning motion, continue his fight, and at the same time, he needs to retrace the possible pathways before the commander reorganizes the maze and creates more roadblocks and dead ends. The sheer size of the Chakra offers the commander nearly infinite ways of creating roadblocks and final dead-ends, as depicted in Fig. 7. He can swiftly rearrange the entire Chakra out of many possibilities and can create free-lanes or narrow gaps for the warrior. As such, there seems to be no predefined rule of escaping the vyuh; it can only be realized within the Chakravyuh while it is in action. Since the escape route can only be devised and fine-tuned on the go, a warrior requires incredibly fast analytical skills. Only a few warriors in the past possessed this attribute and, as such, there were only a few legendary warriors who could destroy a Chakravyuh.

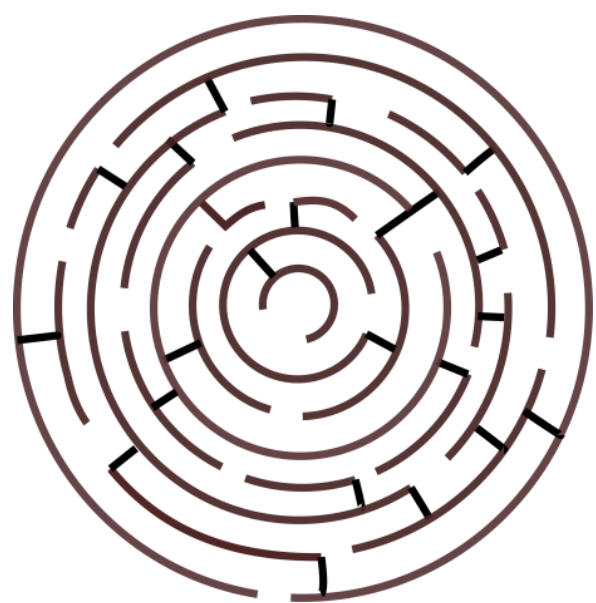

Figure 7. Rearrangement of the whole Chakra to crush the enemy.

A successful trick of reaching the core of the Chakra lies in how familiar the invading warrior is with the skills and strength of interior warriors. This helps him accurately figuring out some vulnerable area and potential point of conflict where he can launch a pre-emptive attack and quickly move away to another place. This movement is necessary in order to avoid getting trapped. As soon as the invading warrior starts creating havoc, there is a high chance of getting trapped because in the meantime the commander would redesign the maze and create roadblocks. The invading warrior needs to perform his action in a meticulous way such that his little effort can cause long-lasting effects and diverts the commander's attention in maintaining the formation. Meanwhile, the warrior can change his angle of attack so that the commander is unable to get enough scope for making dead-ends. This way warrior can devise a smarter strategy to reach the core of the Chakravyuh. There are some other clever tricks of approaching the core. One of the tricks is to keep the archers of the inner layer engaged so that they remain busy in defending themselves instead of attacking the enemy. In extreme 
danger, one can also play the trick, although unethical, to kill the drummer that would break the formation into chaos as stopping the drumbeats would break the rhythms of soldiers.

If a warrior somehow manages to destroy the core of the Chakra, he needs to exit from the giant formation. Exiting the Chakravyuh is a much more difficult task than entering. During the entering phase, the Chakravyuh works in a slow-kill approach. Once the core is destroyed, the exiting phase takes an instant-kill approach and all the troops jump upon the warrior. As such, there seems to be no route to escape from the Chakravyuh after destroying its core except using some art of deceit like a Trojan-horse.

So far, our above descriptions on Chakravyuh focuses on its inherent dynamics from which one would arrive at the conclusion that the clockwise-anticlockwise movement of soldiers in the layers is necessary in order to ensure the existence of the whole maze and, at the same time, in creating an illusion. That the synchronized movement of the infantrymen is closely interwoven with the spinning motion of the Chakra about its axis, is the key to the perplexing puzzle that slackens the mental strength of an enemy warrior. The warrior gradually loses all his physical strength due to strategically distributed strength of the troop and finally, the creation of roadblocks and dead ends out of nearly infinite possible ways doomed to lose his life. Curiosity however remains as to how such a structure is devised or what is its underlying geometry. Below, we use some elementary geometry to elucidate the construction of such an invincible magical defense.

\section{THE GEOMETRY OF CHAKRAVYUH}

To begin with, let us try to draw a nascent Chakravyuh geometrically. The simplest way of drawing a seven-layered Chakravyuh requires a spiral comprising seven equidistant loops, as shown in Fig. 8(a). Although we have shown here a clockwise moving spiral, an anticlockwise spiral will also produce the same result, the only difference will be the position of the entrance. After drawing the spiral, the loops are labeled in reverse order starting from the center. Now a vertical line pointing towards the center is used to connect the endpoint of the spiral to the loop 5. Another two lines are drawn equidistant from the previous line that connects loops 2 and 4.

In the second step, as shown in Fig. 8(b), the portion in between the two smaller lines is erased. In Fig. 8(b) onwards, we have shown a zoom-in view of the outer loops for better visibility. In the third step, the loop 3 is disjoined from the rest of the figure, as shown in Fig. 8(c). Finally, this results in a perfect seven-layers Chakravyuh, as shown in Fig. 8(d).

The above method of drawing is a rudimentary one and does not involve any template for generating the pattern. As we see in mathematics, most of the natural and man-made complicated structures involve a seed or a template. Thus it is natural that there might be some basic template embedded in a Chakravyuh. To create such a seed, let us carefully observe the geometry of the Chakravyuh. As displayed in Fig. 9, if we join the center of the Chakra with the terminating points located at loop 3 on the right and loop 2 on the left by straight lines, they form a triangle. If we perfectly choose the locations of the endpoints of loop 2 and 3, the inscribed triangle will be an equilateral triangle if we draw a logarithmic spiral, given by $r=$ $a e^{-\theta}$ with $a=1$. In that case, all three sides will be intersected by the loops and create four equal segments on each side. This equilateral triangle whose vertex is located at the center of the Chakra and the baseline is the one which connects the disjoint arcs (spirals 3 on the right and 2 on the left), can be treated as a seed for the whole pattern. In Fig. 10, we extract out the triangle for better visibility. The labeling of the segments begins from the center segment of 
the baseline and it goes from 1 to 7 in the anticlockwise direction, the vertex of the triangle being labeled as 7. On the other side of the triangle, the labeling of the segments is done in reverse order where the vertex is labeled as 6 so that the two consecutive segments of the baseline acquire the same labeling as 1,1 . This will be clear after a short while as to why the labeling is done in such a particular fashion.

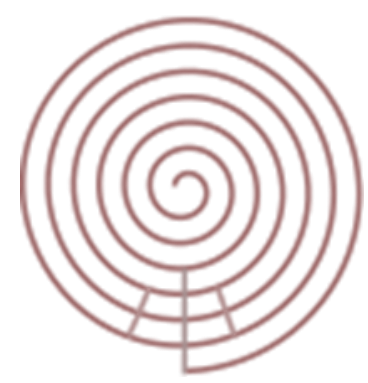

(a)

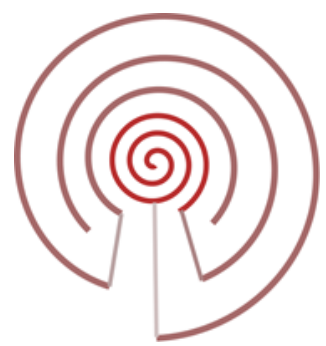

(c)

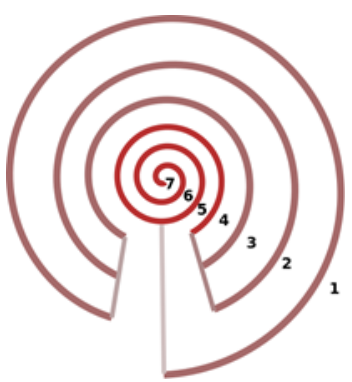

(b)

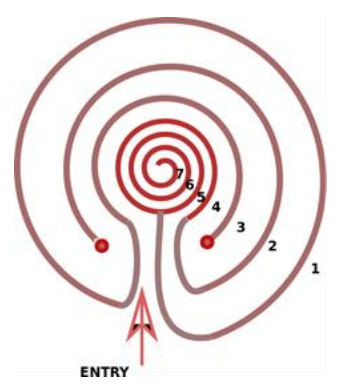

(d)

Figure 8. The steps involved in constructing a nascent Chakravyuh from a spiral. It involves a few steps: (a) drawing a logarithmic spiral $(\llbracket r=e \rrbracket \wedge(-\theta))$ with 7 loops and leveling them in reverse order starting from the center, connecting the endpoint with loop 5 by a vertical line pointing towards the center, and connecting the spirals 2 and 4 by another two lines (b) erasing a portion between the spirals 4 and 2 (c) disconnecting the spiral 3 from the lines and (d) making a narrow path for the entrance.

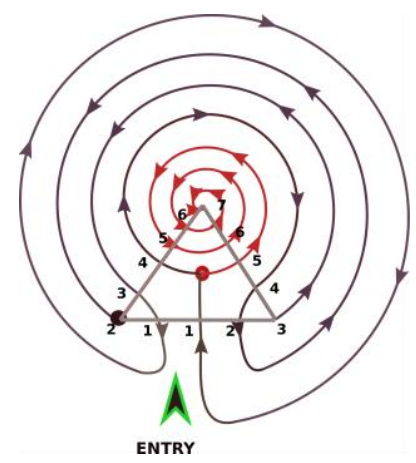

Figure 9. Construction of a basic seed pattern.

To construct the whole pattern, let us begin with the point 7 located on the top of the triangle and proceed towards the point 6 on the left arm by drawing a clockwise-rotating spiral, as depicted in Fig. 10. As we continue the spiral with gradually increasing radii that goes from 6 to $6,5-5,4-4,3-3,2-2$, and 1-1, it forms a complete seven-layered Chakravyuh and the labeling of the layers exactly matches with that of Fig. 8. In order to do so, the trick lies in labeling the points on the sides of the triangle. If we want to start with an anticlockwiserotating spiral (not shown here), the labeling of the segments on the seed pattern needs to be 
reversed. In that case, the entrance will appear on the other side. In either case, the seed pattern will remain the same and acts as the heart of the Chakravyuh.
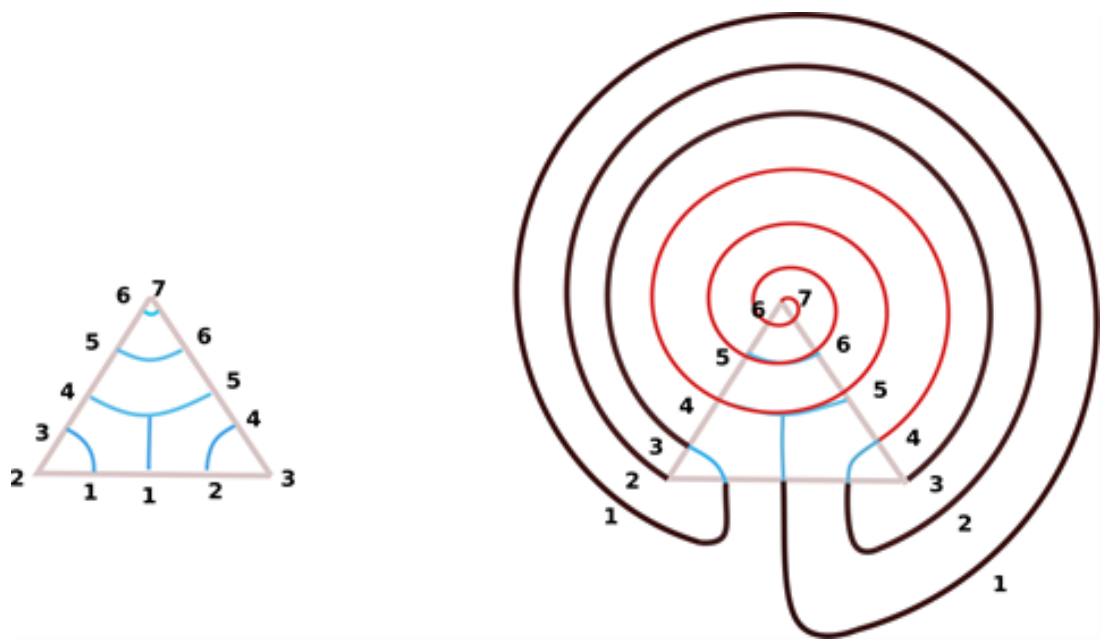

Figure 10. The triangle is a basic seed pattern for Chakravyuh construction. (a) Labeling the segments on each side of the triangle (b) connecting equal numbers by segments of a spiral completes the Chakravyuh.

The seed that we show is basically an equilateral triangle whose perpendicular bisectors meet at the centroid. This structure, as shown in Fig. 11, is rotationally invariant about the perpendicular bisectors. This symmetry belongs to dihedral 3 or, simply $D_{3}$ group by an angle of $120^{\circ}$, indicating that we can choose any of the sides as the base without distracting the structure. That is the reason that the whole troop that forms the Chakravyuh in a battlefield can rotate continuously about its axis, keeping intact its structure.
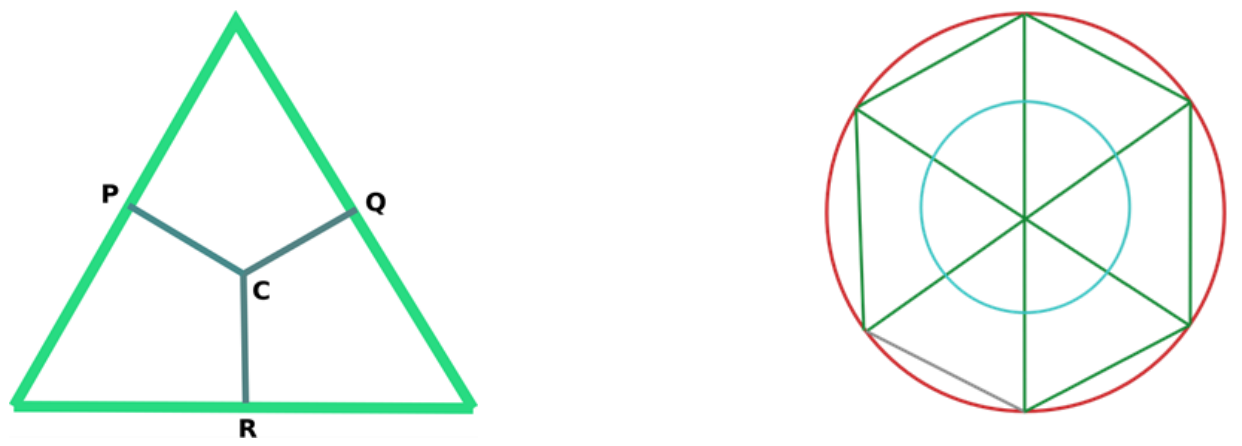

Figure 11. An equilateral triangle where three perpendicular bisectors $\mathrm{PC}, \mathrm{QC}$, and $\mathrm{RC}$ meet at the centroid (b) the rotation of the triangle about a vertex circumscribes a circle while the centroids lie in another (inner) circle.

How a Chakravyuh looks like when it rotates about its center? This can be easily visualized by looking at the rotation of the seed pattern. Rotation of an equilateral triangle about any one of its vertices circumscribes a circle while the centroids lie in another (inner) circle. This is shown in Fig. 11(b) only for six discrete rotations. The inner circle is basically the trajectory of centroids (point $\mathrm{C}$ ) of each triangle. If we make a comparison of Fig. 10 with Fig. 11, it will be immediately obvious that the centroid of the equilateral triangle is the point where the vertical line touches layer 5 of the Chakravyuh. This is also the junction of two different wings of soldiers, one from the outer layer (shown black in color) and the other from the inner layer (shown red in color). Eventually, the soldiers at the position of centroid need to be extremely cautious. They must avoid crossing each other and at the same time, they need to 
revolve in a circular path. As such, this is the weakest point of Chakravyuh formation and vulnerable to a skilled enemy warrior.

\section{EPILOGUE}

With a little textual and archaeological evidence about the details of Chakravyuh, here we have offered with our own speculation a detailed analysis that might decipher its underlying complexity as to why such a battle formation has remained nearly invincible even for highly skilled warriors of antiquity. What lies at the heart of its complexity is the nearly infinite possible ways of its rearrangement that can simultaneously impose physical, psychological, and strategic attack on the enemy forces.

With rapid advances in computer hardware and visualization systems, scientists and engineers are nowadays able to perform exact geometric computation on any complex shapes with the help of incredibly efficient algorithms [15]. The crowning intellectual achievements in computational geometry provide a great opportunity for representation, manipulation, and analysis of any complex shape. As we have described above, at the heart of the complex geometry of Chakravyuh lies some deep mathematical issues concerned with its representation, computation, and manipulation. Now it is the turn of modern mathematicians, engineers, and computer scientists to open such treasure-trove of ancient marvels, decipher the puzzle, unravel the inherent mystery and enchant the world with the pearls of ancient wisdom.

\section{REFERENCES}

[1] Singha, K.: Mahabharata.

Basumati Sahitya Mandir, Kolkata. 2005,

[2] Chakravarti, P.C.: The art of war in ancient India.

Kalpaz publications, New Delhi, 2019,

[3] Tripathi, R.S.: History of ancient India.

Motilal Banarasidass, Delhi, 2006,

[4] Hooper, C.: The Mahabharata.

Psychological Perspectives 61(1), 76-91, 2018, http://dx.doi.org/10.1080/00332925.2018.1422931,

[5] Rao, S.R.: From Dvaraka to Kurukshetra. Journal of Marine Archeology 5-6, 61-71, 1995,

[6] Gombach, B.; Larsen, G.J. and Hudson, E.T.: The Mahabhartata: What is Not Here is Nowhere Else.

Munshiram Manoharlal Publishers, New Delhi, 2005,

[7] Gombach, B.: Ancillary stories in the Sanskrit Mahabharata. Ph.D. Thesis.

Columbia University, New York, 2000,

[8] Rosen, S.P.: Societies and Military Power: India and its Armies.

Cornell University Press, New York, 1996,

[9] Greenhut, J.: Armies of India from the Aryans to the Marathas.

Journal of the United Service Institution of India 106(442), 30-41, 1976,

[10] Barua, P.P.: The State at War in South Asia.

The American Historical Review 111(1), 139-140, 2006,

http://dx.doi.org/10.1086/ahr.111.1.139-a,

[11] Prasad, S.N.: Historical Perspectives of Warfare in India: Some Morale and Material Determinants.

Centre for Studies in Civilizations in association with Motilal Banarasidass, New Delhi, 2002,

[12] Thapliyal, U.P.: Warfare in Ancient India: Organizational and Operational Principles. Manohar, New Delhi, 2010, 
[13] Wikimedia: https://commons.wikimedia.org/wiki/File:Halebid2.JPG,

[14] Bhakari, S.K.: Indian warfare: an appraisal of strategy and tactics of war in early medieval period.

Munshiram Manoharlal Publishers, New Delhi, 1981,

[15] Zomorodian, A.J.: Topology for Computing.

Cambridge University Press, Cambridge, 2005. 